\title{
Evaluation of the anatomical variation in the nasal cavity and paranasal sinuses of patients with cleft lip and palate using cone beam computed tomography
}

\author{
Dedeoglu $\mathrm{N}^{1}$, Altun $\mathrm{O}^{2}$, Kucuk $\mathrm{EB}^{3}$, Altindis $\mathrm{S}^{4}$, Hatunoglu $\mathrm{E}^{5}$ \\ Inonu University, Faculty of Dentistry, Department of Oral and Dentomaxillofacial Radiology, \\ Malatya, Turkey.dedenu@gmail.com
}

\begin{abstract}
OBJECTIVE: The aim of this study was to evaluate the frequency of anatomical variation in nasal cavity and paranasal sinuses by comparing a unilateral cleft lip and palate (UCLP) group with a non-syndromic control group using cone beam computed tomography (СВCT).

SUBJECTS AND METHODS: This study included 24 UCLP patients in the UCLP group and 24 non-syndromic patients in the control group. Coronal CBCT images were taken in all patients and were evaluated for anatomical variation. The measurements obtained in this study were analysed using chi-square and Fisher's exact tests to compare the two groups statistically.

RESULTS: In the UCLP group, there were statistically lower frequencies of pterygoid process pneumatisation $(p<0.05)$, higher wing pneumatisation $(p<0.05)$, and sphenoid sinus over pneumatisation $(p<0.05)$, and statistically higher frequencies of anterior nasal septal deviation $(p<0.05)$ compared to the control group.

CONCLUSION: A higher incidence of anterior nasal septal deviation was found in UCLP patients compared to the patients in the control group. It is likely that for this reason, UCLP patients might be predisposed to sinusitis. In UCLP patients, the incidence of neurovascular structures in the sphenoid sinus was lower than that in non-syndromic control patients (Tab. 1, Fig. 6, Ref. 33). Text in PDF www.elis.sk.

KEY WORDS: cleft lip and palate, paranasal sinus, anatomical variation, nasal cavity, cone beam computed tomography.
\end{abstract}

\section{Introduction}

The paranasal sinus region is a large varied and complex field (1), and congenital anomalies and anatomical variation may cause difficulties during functional endoscopic sinus surgery (2). Certain anatomical variations in this field may lead to chronic sinusitis and mucosal diseases (3). To prevent damage to adjacent structures, it is important that surgeons are aware of certain anatomic variation prior to performing sinus surgery (2).

Conventional dental imaging methods such as: panoramic and lateral cephalometric radiography are generally used for planning of orthodontic and maxillofacial surgical treatment (4). Nevertheless, conventional radiology has several limitations including providing only a two-dimensional assessment of the skeletal configuration and the fact that structural superimposition does not

${ }^{1}$ Inonu University, Faculty of Dentistry, Department of Oral and Dentomaxillofacial Radiology, Malatya, Turkey, ${ }^{2}$ Inonu University, Faculty of Dentistry, Department of Oral and Dentomaxillofacial Radiology, Malatya, Turkey, ${ }^{3}$ Mustafa Kemal University, Faculty of Dentistry, Department of Orthodontics, Hatay, Turkey, ${ }^{4}$ Private Practice, Kayseri, Turkey, and ${ }^{5}$ Firat University, Faculty of Dentistry, Department of Orthodontics, Elaziğ, Turkey

Address for correspondence: N. Dedeoglu, Inonu University, Dentistry of Faculty Department of Oral and Dentomaxillofacial Radiology, 44280, Malatya, Turkey.

Phone: +90.422.3411106, Fax: +90.422.3411108 allow precise exploration of the sinus region (5). With the advantage of three-dimensional imaging, clinicians are able to observe anatomical structures clearly. Cone beam computed tomography $(\mathrm{CBCT})$ is a useful method for the evaluation of the paranasal sinuses. $\mathrm{CBCT}$ is regarded as equivalent to computed tomography (CT) in obtaining diagnostic information. Moreover, CBCT has some advantages compared to $\mathrm{CT}$, such as a shorter imaging time, low cost, and low radiation exposure (4).

The anatomical variation in paranasal sinuses has been well documented in earlier studies; however, there is a need for additional information regarding UCLP patients. The aim of this study was to evaluate the frequency of anatomical variation in paranasal sinus and nasal cavity by comparing the UCLP group with the control group using CBCT.

\section{Subjects and methods}

CBCT images of 24 unilateral cleft lip, alveolus, and palate patients ( 10 females and 14 males, mean age: $19.9 \pm 7.7$ years old; min: 16, max: 41) and 30 non-syndromic patients ( 9 females and 15 males, mean age: $19.9 \pm 7.7$ years old; min: 16 , max: 45$)$ were retrospectively evaluated from the archives of the University, Faculty of Dentistry, Department of Oral and Dentomaxillofacial Radiology.

CBCT images in the UCLP group were part of the diagnostic records collected during the preoperative examination prior to 

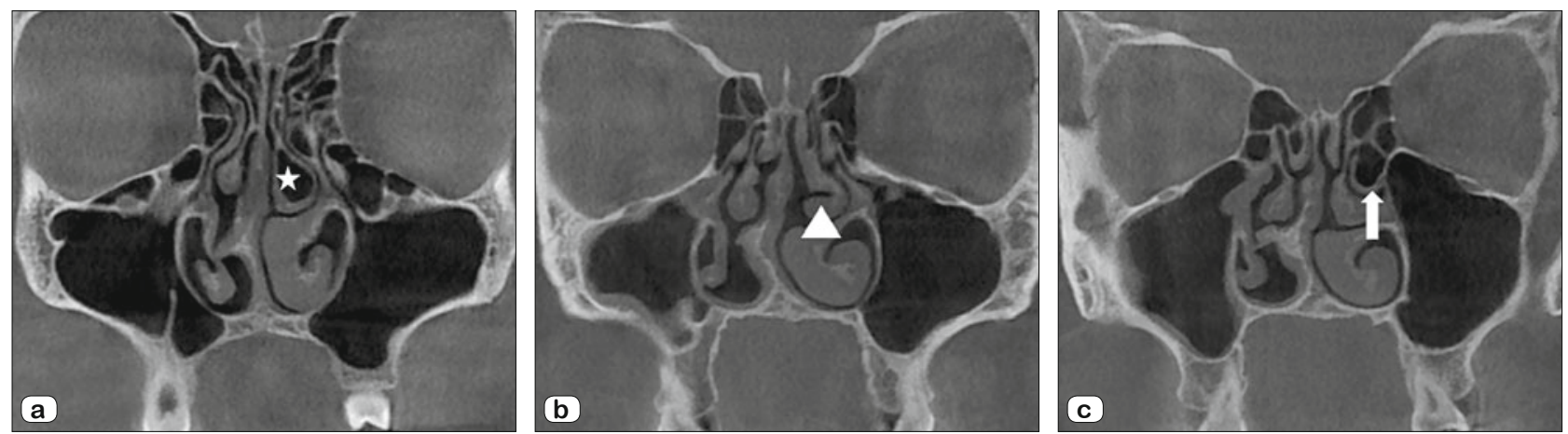

Fig. 1. In coronal CBCT scan, (a) concha bullosa (asterix), (b) paradoxical middle concha (arrowhead), (c) secondary middle concha (arrow).
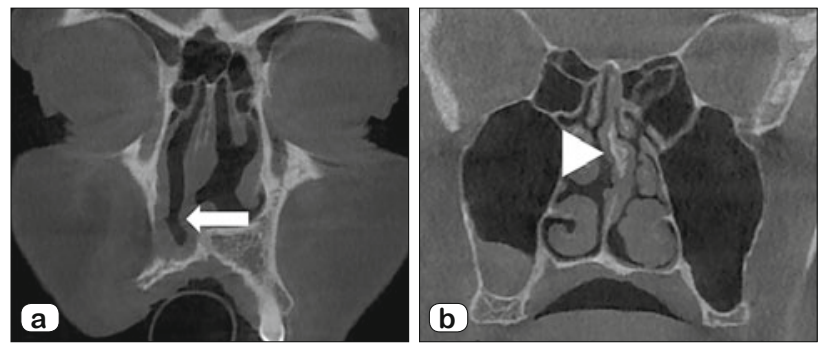

Fig. 2. In coronal CBCT scan, nasal septal deviation anterior (arrow) and posterior part (arrowhead).

orthodontic treatment, and those in the control group were from patients, who had undergone a CBCT scan for any other reason. Some patients were excluded from this study according to the following exclusion criteria:

- Advanced inflammatory diseases, nasal polyposis, or serious rhinosinusitis.

- History of skull base, face, and nasal trauma.

- Prior sinonasal surgery.

The study field determined the anterior wall of the frontal sinus to the posterior wall of the sphenoid sinus in the horizontal plane and the inferior wall of the maxillary sinus to the upper wall of the frontal sinus in the vertical plane.

All CBCT images included in the present study were evaluated by the same experienced maxillofacial radiologist.
To obtain CBCT images, a Newtom 5G (Verona, Italy) device was used. The kilo voltage setting was 110 , with an intensity of 1-20 mA, a scanning time of $18 \mathrm{~s}$, an exposure time of $3.6 \mathrm{~s}$, and voxel sizes of $0.2,0.25$, or $0.3 \mathrm{~mm}^{3}$. Coronal CBCT sections (1$\mathrm{mm}$ thickness and 1-mm step) were used for the evaluation of the anatomical variation in nasal cavity and paranasal sinuses in both groups. This disease was evaluated as either being present or absent. Anatomical variation evaluated in this study is summarized below:

\section{1) Conchal Variation}

- Concha bullosa (CB): pneumatisation of the middle concha (Fig. 1a) (6).

- Paradoxical middle concha (PMC): the convex portion of the concha is on the opposite side, and it usually occurs in the middle concha (Fig. 1b) (7).

- Secondary middle concha (SMC): a bony projection that arises from the lateral nasal wall and extends into the nasal cavity (Fig. 1c) (8).

\section{2) Septal Variation}

- Nasal septal deviation (anterior and posterior part) (ANSDPNSD): tilting of the septum (Figs 2a-b).

3) Maxillary Variation

- Maxillary sinus hypoplasia (MSH): the maxillary sinus maxi-
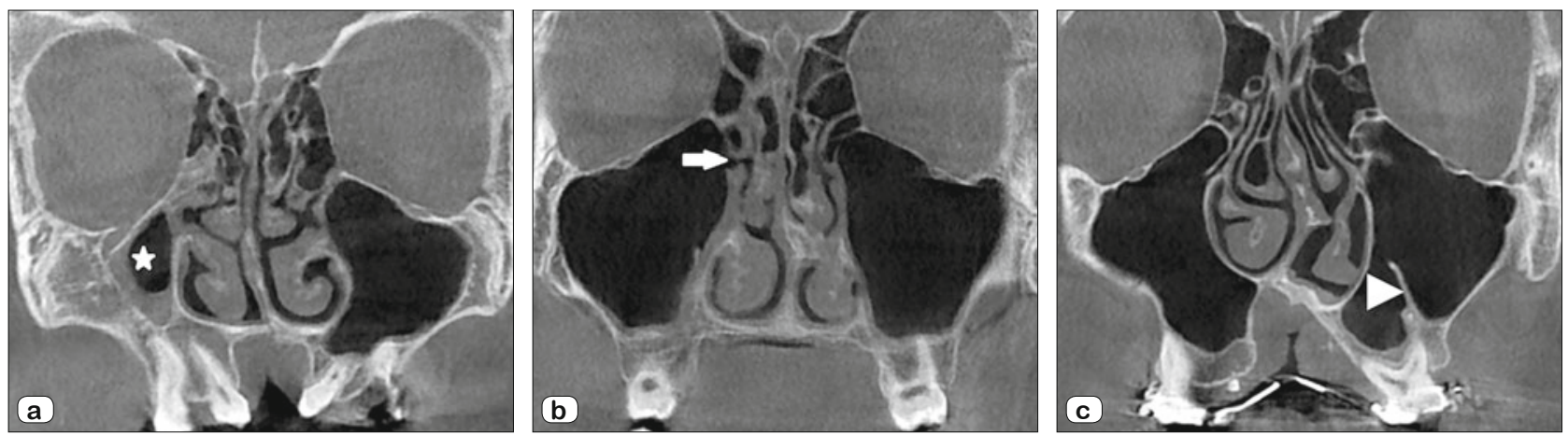

Fig. 3. In coronal CBCT scan, (a) maxillary sinus hypoplasia (asterix), (b) maxillary sinus accessory ostium (arrow), (c) maxillary sinus septum (arrowhead). 


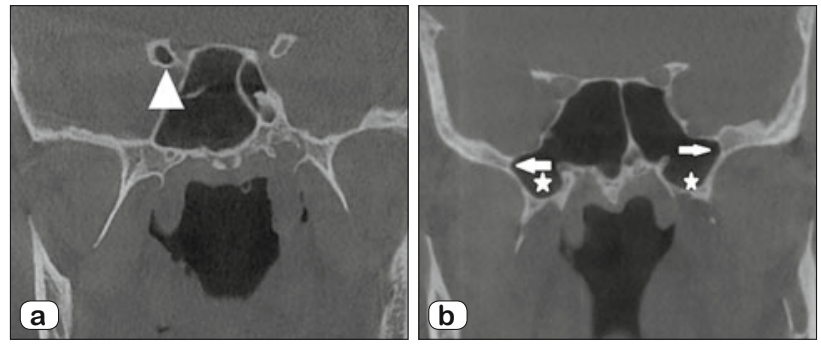

Fig. 4. In coronal CBCT scan, (a) anterior clinoid process pneumatization (arrowhead), (b) pterygoid process pneumatization (asterix) and greater wing pneumatization (arrows).

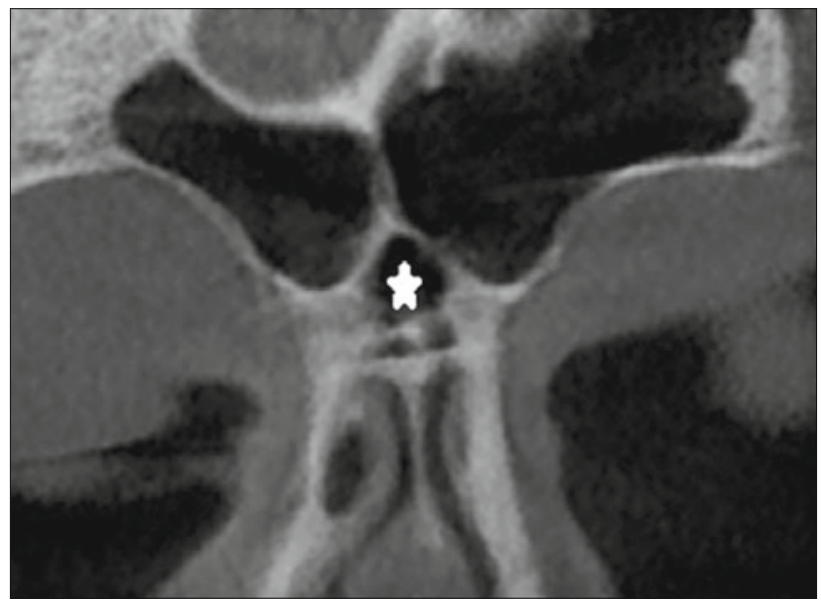

Fig. 5. In coronal CBCT scan, interfrontal sinus septal cell (asterix).

mum vertical or horizontal length is less than half the orbital maximum vertical or horizontal length (Fig. 3a) (9).

- Maxillary sinus accessory ostium (MSAO): an extra ostium in addition to the natural ostium (Fig. 3b) (10).

- Maxillary sinus septum (MSS): a cortical bone projection into the sinus that arises from the inferior or lateral walls of the sinus (Fig. 3c) (11).

4) Sphenoidal Variation

- Anterior clinoid process pneumatisation (ACPP): extension of the sinus cavity into the anterior clinoid process (Fig. 4a).
- Pterygoid process pneumatisation (PPP): extension of the sinus cavity beyond the vertical line of the foramen rotundum (Fig. 4b) (12).

- Greater wing pneumatisation (GWP): extension of the sinus cavity beyond the vidian canal in the horizontal plane (Fig. 4b) (12).

- Sphenoid sinus over pneumatisation (SSOP): occurrence of at least one of the following conditions in the sphenoid sinus; anterior clinoid process pneumatisation, pterygoid process pneumatisation, and greater wing pneumatisation.

\section{5) Frontal Variation}

- Inter-frontal sinus septal cell (IFSC): appearance of a pneumatisation into the inter-frontal sinus septum (Fig. 5) (13).

\section{6) Ethmoidal Variation}

- Kuhn cell (KC): cell located above the agger nasi cell, and with several types (Fig. 6a) (14).

- Agger nasi cell (ANC): the most anterior ethmoid cell (Fig. 6b) (2).

- Haller cell (HC): develops under the medial orbital floor and medial roof of the maxillary sinus (Fig. 6c) (7).

- Onodi cell (OC): the most posterior ethmoid cell, located in the posteromedial sphenoid sinus (Fig. 6d) (15).

When more than one variation such as ACPP, PPP, and GWP was observed in the sphenoid sinus, the condition was accepted as sphenoid sinus over pneumatisation. Nasal septal deviation was evaluated as the anterior (region of the condrovomeral junction) and the posterior (back of the condrovomeral junction) parts.

Chi-square and Fisher's exact tests were used for statistical analysis of the differences between the UCLP and control groups $(\mathrm{p}<0.05)$.

\section{Results}

The frequencies and $p$ values of the anatomical variation in the nasal cavity and paranasal sinuses of the UCLP and control groups are presented in Table 1. The most common anatomical variation was found to be ANC (100\%) in both groups. The least anatomical variation was found to be $\mathrm{MSH}(4.2 \%)$ and $\mathrm{ACPP}(4.2$ $\%)$ in the UCLP group and MSH (0\%) in the control group. Sta-
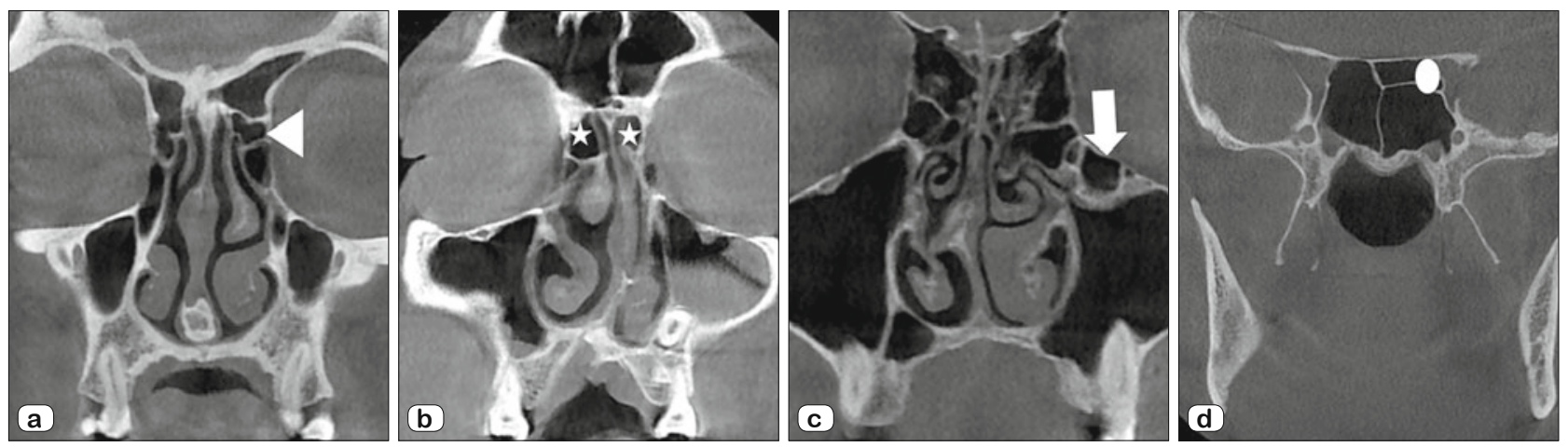

Fig. 6. In coronal CBCT scan, (a) kuhn cell (arrowhead), (b) agger nasi cell (asterix), (c) haller cell (arrow), (d) onodi cell (circle). 
Tab. 1. The distribution of the anatomical variations according to the groups.

\begin{tabular}{|c|c|c|c|}
\hline Nasal Cavity and Paranasal Sinus Anatomical Variations & CLP group n (\%) & Control group n $(\%)$ & Inter-group comparisons $¥$ \\
\hline Concha Bullosa & $21(87.5)$ & $20(83.3)$ & ns \\
\hline$\underline{\text { Paradoxical Concha }}$ & $11(45.8)$ & $9(37.5)$ & ns \\
\hline Secondary Middle Concha & $22(91.7)$ & $20(83.3)$ & ns \\
\hline Anterior Nasal Septal Deviation & $22(91.7)$ & $11(45.8)$ & $* * *$ \\
\hline Posterior Nasal Septal Deviation & $22(91.7)$ & $16(66.7)$ & ns \\
\hline Nasal Septal Spur & $13(54.2)$ & $11(45.8)$ & ns \\
\hline Maxillary Sinus Accessory Ostium & $13(54.2)$ & $11(45.8)$ & ns \\
\hline Maxillary Sinus Septum & $12(50)$ & $8(33.3)$ & ns \\
\hline Anterior Clinoid Process Pneumatization & $1(4.2)$ & $4(16.7)$ & ns \\
\hline Pterygoid Process Pneumatization & $6(25)$ & $15(62.6)$ & $* *$ \\
\hline Greater Wing Pneumatization & $5(20.8)$ & $16(66.7)$ & $* * *$ \\
\hline Sphenoid Sinus Over Pneumatization & $7(29.2)$ & $16(66.7)$ & $* *$ \\
\hline Interfrontal Sinus Septal Cell & $15(62.5)$ & $8(33.3)$ & $*$ \\
\hline Haller Cell & $10(41.7)$ & $7(29.2)$ & ns \\
\hline Onodi Cell & $6(25)$ & $3(12.5)$ & ns \\
\hline Kuhn Cells & $19(79.2)$ & $19(79.2)$ & $\mathrm{ns}$ \\
\hline
\end{tabular}

$¥$ According to Chi-square and Fisher’s exact tests; $* * * \mathrm{p}<0.001, * * \mathrm{p}<0.01, * \mathrm{p}<0.05, \mathrm{~ns}-$ there is no statistically significant difference, $\mathrm{n}-$ number of samples, SD standard deviation

tistically significant differences were found in pterygoid process pneumatisation, greater wing pneumatisation, SSOP, and ANSD between the UCLP and control groups $(\mathrm{p}<0.05)$.

\section{Discussion}

CLP holds an important place among birth abnormalities, and its prevalence is 1/800-1000 in non-syndromic patients (16). In patients with UCLP, middle ear and mastoid problems, dental anomalies, and maxillary sinus volume shortage are observed frequently $(17,18)$. Recently, investigations into nasal cavity and paranasal sinuses in CLP patients had increased, because rhinosinusitis was commonly observed in these patients (19). The treatment of these patients is jointly performed by several disciplines such as: otorhinolaryngology, prosthetic dentistry, oral and maxillofacial or plastic surgery, and orthodontics. However, the anatomical structures in these patients may be different from normal anatomy; thus, abnormalities should be evaluated carefully before the treatment. Therefore, the frequency of the anatomical variation of the nasal cavity and paranasal sinuses was evaluated in UCLP patients using CBCT in this study.

\section{Conchal variation}

Conchal anatomical variation (CB, PMC, and SMC) was evaluated in the present study; however, no significant differences between the UCLP and control groups were found. CB and SMC were found at a high rate in both groups; however, these only obstructed the middle meatus and osteomeatal unit, causing sinusitis $(8,20)$, if they were severe.

\section{Nasal septal variation}

Nasal septal deviation is the tilting of the septum, a malformation that is expected and often observed in UCLP patients. UCLP leads to enlargement of the nose wings, thus, the tip of the nose points towards the cleft side and the septal base points towards the non-cleft side (21), leading to nasal septal deviation, especially in the anterior part. According to the results of the present study relating to septal variations, the frequency of anterior nasal septum deviation in the UCLP group was significantly larger than in the control group $(\mathrm{p}<0.05)$, which is in accordance with previous results presented in the literature (22). However, there was no difference in terms of PNSD. Advanced septal deviation may lead to a narrow or blocked meatus, pushing the middle concha towards the lateral wall. This situation also increases the risk of secondary inflammation and infection (23).

Yasan et al (24) found that only severe nasal septal deviation is a risk for chronic rhinosinusitis. In particular, when nasal septal deviation is located in the nasal valve area, a patient will be more predisposed to rhinosinusitis $(25,26)$. Kuijpers et al $(17)$ reported that the frequency of nasal septal deviation in UCLP patients was $34 \%$, however, in our UCLP group, this frequency was found to be $91.7 \%$ in both the anterior and posterior parts. The reason for this difference is likely due to the fact that both bilateral and unilateral CLP patients were evaluated in the study by Kuijpers et al (17) whereas in our study, only UCLP patients were examined.

\section{Maxillary variation}

When the maxillary sinus variation was evaluated, there were no statistically significant differences in MSH, MSAO, or MSS between the UCLP and control groups. MSH may cause a reduction in drainage due to the malposition of the ostium, resulting in a predisposition to sinusitis $(19,27)$.

MSAO occurs when there is an extra ostium in addition to the natural ostium, providing a connection between the maxillary sinus and the middle meatus (28), which may cause sinusitis by allowing easier pathogen access (29). MSS is important for implant surgery, since the membrane perforation risk increases in the presence of this variation (30). 


\section{Sphenoidal variation}

Sphenoid sinus is a critical sinus due to its relationships with important adjacent structures. During the process of development, sinus and neighbouring structures may show various variations (31). ACPP is one of the most important sphenoid sinus variations, and is also seen anatomically near the optic nerve, internal carotid artery, and ophthalmic artery. These important structures may be damaged during surgery in the case of ACPP (32). Şirikci et al (31) evaluated patients with chronic inflammatory disease of the nasal cavity and paranasal sinuses, and reported that the rate of ACPP was $13.3 \%$. However, in our study, the frequency of ACPP was found to be only $4.2 \%$ in the UCLP group, which reduced the potential risks.

The other three sphenoid sinus variations evaluated in the present study (PPP, GWP, and SSOP) showed differences between groups, being significantly lower in the UCLP group than in the control group $(\mathrm{p}<0.05)$.

PPP is an important way to reach the base of the skull, and treatment of CSF leakage and endoscopic biopsy from skull base lesions can be conducted via this route (12). According to the results of the present study, PPP frequency was lower in the UCLP group than in the control group $(\mathrm{p}<0.05)$, and therefore, it is considered that patients with UCLP are deprived of this advantage.

GWP is a pneumatisation beyond the vertical line of the foramen rotundum in the sphenoid sinus (12). The number of studies in literature regarding this variation is inadequate.

The last sphenoid sinus variation is SSOP, where the optic, vidian, and maxillary nerves may be located in the sphenoid sinus. According to the results of the present study, SSOP was found statistically more frequently in the control group than in the UCLP group. This finding in UCLP patients is the first information in literature regarding sphenoid sinus pneumatisation. This information suggests that, compared to the patients with UCLP, more neurovascular structures may be located in the sphenoid sinus in normal patients, and therefore the risk of complications during surgery is lower in patients with UCLP than in normal patients.

\section{Frontal variation}

IFSC is the appearance of a pneumatisation in the inter-frontal septum (13). The clinical significance of this variation is uncertain (33), and there was no significant difference between the groups.

\section{Ethmoidal variation}

ANC is the most anterior ethmoid cell, and large ANC may narrow the frontal recess (2). Ocular complications develop in the case of sinus disease, which is related to ANC, since ANC is in close proximity to the lacrimal sac (2). ANC was observed in all patients in both groups, and there were no significant differences between the two groups. This high frequency shows that correct localization of ANC is very important for the diagnosis and treatment of sinusitis. KC (frontal cell) is located in the upper ANC, and $\mathrm{HC}$ develops under the medial orbital floor and the medial roof of the maxillary sinus, both of which may also lead to sinusitis $(7,14)$. OC is the most posterior ethmoid cell, located in to posteromedial sphenoid sinus. OC may be in close proximity to the optic nerve, which is important for surgery (15). In our study, there were no statistically significant differences in ANC, $\mathrm{HC}$, or OC between the UCLP and control groups.

\section{Conclusions}

In UCLP groups, ANSD was seen more frequently than in the control groups, and for this reason, UCLP groups may be more predisposed to sinusitis compared to normal individuals.

In UCLP groups, pterygoid process pneumatisation, greater wing pneumatisation, and SSOP was seen less frequently than in control patients. Clinically, this information is important for endoscopic surgery of the sphenoid sinus in UCLP groups.

In further studies, anatomical variation in the nasal cavity and paranasal sinuses should be examined in subgroups of the CLP groups.

\section{References}

1. Keast A, Yelavich S, Dawes P, Lyons B. Anatomical variations of the paranasal sinuses in Polynesian and New Zealand European computerized tomography scans. Otolaryngol Head Neck Surg 2008; 139: 216-221.

2. Kantarci M, Karasen RM, Alper F, Onbas O, Okur A, Karaman A. Remarkable anatomic variations in paranasal sinus region and their clinical importance. Eur J Radiol 2004; 50: 296-302.

3. Fadda G, Rosso S, Aversa S, Petrelli A, Ondolo C, Succo G. Multiparametric statistical correlations between paranasal sinus anatomic variations and chronic rhinosinusitis. Acta Otorhinolaryngol Ita 2012; 32: 244-251.

4. Wörtche R, Hassfeld S, Lux C, Müssig E, Hensley F, Krempien R et al. Clinical application of cone beam digital volume tomography in children with cleft lip and palate. Dentomaxillofac Radiol 2006; 35: 88-94.

5. Perez-Pinas I, Sabate J, Carmona A, Catalina-Herrera C, JimenezCastellanos J. Anatomical variations in the human paranasal sinus region studied by CT. J Anat 2000; 197: 221-227.

6. Stallman JS, Lobo JN, Som PM. The incidence of concha bullosa and its relationship to nasal septal deviation and paranasal sinus disease. Am J Neuroradiol 2004; 25: 1613-1618.

7. Azila A, Irfan M, Rohaizan Y, Shamim A. The prevalence of anatomical variations in osteomeatal unit in patients with chronic rhinosinusitis. Med J Malaysia 2011; 66: 191-194.

8. Ozturk A, Alataş N, Ozturk E, Ziylan SZ. First secondary middle turbinate. Eur J Radiol 2004; 52: 93-95.

9. Sirikci A, Bayazit Y, Bayram M, Kanlikana M. A new approach to the classification of maxillary sinus hypoplasia with relevant clinical implications. Surg Radiol Anat 2001; 22: 243-247.

10. Na Y, Kim K, Kim SK, Chung SK. The quantitative effect of an accessory ostium on ventilation of the maxillary sinus. Respir Physiol Neurobiol 2012; 181: 62-73.

11. Maestre-Ferrín L, Galán-Gil S, Rubio-Serrano M, PeñarrochaDiago M, Peñarrocha-Oltra D. Maxillary sinus septa: a systematic review. Med Oral Patol Oral Cir Bucal 2010; 15: 383-386.

12. Hewaidi G, Omami G. Anatomic variation of sphenoid sinus and related structures in Libyan population: CT scan study. Libyan J Med 2008; 3: 1-9. 
691-696

13. Merritt RM, Bent JP, Kuhn FA. The intersinus septal cell: anatomic, radiologic, and clinical correlation. Am J Rhinol 1996; 10: 299-302.

14. Bent JP, Cuilty-Siller C, Kuhn FA. The frontal cell as a cause of frontal sinus obstruction. Am J Rhinol 1994; 8: 185-191.

15. Weinberger DG, Anand VK, Al-Rawi M, Cheng HJ, Messina AV. Surgical anatomy and variations of the Onodi cell. Am J Rhinol 1996; 10: $365-370$.

16. Cooper ME, Ratay JS, Marazita ML. Asian oral-facial cleft birth prevalence. Cleft Palate Craniofac J 2006; 43: 580-589.

17. Kuijpers MA, Pazera A, Admiraal RJ, Bergé SJ, Vissink A, Pazera

P. Incidental findings on cone beam computed tomography scans in cleft lip and palate patients. Clin Oral Investig 2014; 18: 1237-1244.

18. Erdur O, Ucar FI, Sekerci AE, Celikoglu M, Buyuk SK. Maxillary sinus volumes of patients with unilateral cleft lip and palate. Int J Pediatr Otorhinolaryngol 2015; 79: 1741-1744.

19. Suzuki H, Yamaguchi T, Furukawa M. Rhinologic computed tomographic evaluation in patients with cleft lip and palate. Arch Otolaryngol Head Neck Surg 1999; 125: 1000-1004.

20. Maru Y, Gupta Y. Concha bullosa: frequency and appearances on sinonasal CT. Indian J Otolaryngol Head Neck 1999; 52: 40-44.

21. Pai BCJ, Ko EWC, Huang CS, Liou EJW. Symmetry of the nose after presurgical nasoalveolar molding in infants with unilateral cleft lip and palate: a preliminary study. Cleft Palate Craniofac J 2005; 42: 658-63.

22. Sandham A, Murray J. Nasal septal deformity in unilateral cleft lip and palate. Cleft Palate Craniofac J 1993; 30: 222-226.

23. Laine F, Smoker W. The ostiomeatal unit and endoscopic surgery: anatomy, variations, and imaging findings in inflammatory diseases. Am J Roentgenol 1992; 159: 849-857.

24. Yasan H, Doĝru H, Baykal B, Döner F, Tüz M. What is the relationship between chronic sinus disease and isolated nasal septal deviation? Otolaryngol Head Neck Surg 2005; 133: 190-193.
25. Prasad S, Varshney S, Bist S, Mishra S, Kabdwal N. Correlation study between nasal septal deviation and rhinosinusitis. Indian J Otolaryngol Head Neck 2013; 65: 363-366.

26. Mladina R, Čujić E, Šubarić M, Vuković K. Nasal septal deformities in ear, nose, and throat patients: an international study. Am J Otolaryngol 2008; 29: 75-82.

27. Ishikawa Y, Kawano M, Honjo I, Amitani R. The cause of nasal sinusitis in patients with cleft palate. Arch Otolaryngol Head Neck Surg 1989; 115: 442-446.

28. Beale TJ, Madani G, Morley SJ. Imaging of the paranasal sinuses and nasal cavity: normal anatomy and clinically relevant anatomical variants.Semin Ultrasound CT MR 2009; 30: 2-16.

29. Matthews BL, Burke AJ. Recirculation of mucus via accessory ostia causing chronic maxillary sinus disease. Otolaryngol Head Neck Surg 1997; 117: 422-423.

30. Lee WJ, Lee SJ, Kim HS. Analysis of location and prevalence of maxillary sinus septa. J Periodontal Implant Sci 2010; 40: 56-60.

31. Şirikci A, Bayazit Y, Bayram M, Mumbuc S, Güngör K, Kanlikama M. Variations of sphenoid and related structures. Eur Radiol 2000; 10: 844-848.

32. Cheng Y, Wang C, Yang F, Duan Y, Zhang S, Wang J. Anterior clinoid process and the surrounding structures. J Craniomaxillofac Surg 2013; 24: 2098-2102.

33. Wang M, Yuan F, Qi W, Cheng J, Yuan X, Han L et al. Anatomy, classification of intersinus septal cell and its clinical significance in frontal sinus endoscopic surgery in Chinese subjects. Chin Med J 2012; 125 : $4470-4473$.

Received August 5, 2016. Accepted August 17, 2016. 